\title{
The imprinted H19 gene is a marker of early recurrence in human bladder carcinoma
}

\author{
I Ariel, M Sughayer`, Y Fellig ${ }^{\star}$, G Pizov, S Ayesh, D Podeh, B A Libdeh, C Levy,
} T Birman, M L Tykocinski, N de Groot, A Hochberg

\begin{abstract}
Department of Pathology and the Quantitative Molecular Pathology Unit, Hadassah Medical Centre and the Hebrew University-Hadassah Medical School, PO Box 24035, il-91240, Israel

I Ariel

Y Fellig

G Pizov

C Levy

T Birman
\end{abstract}

Department of Urology, Hadassah Medical Centre and the Hebrew

University-Hadassah

Medical School, PO

Box 12000, il-91120,

Israel

D Podeh

Department of Biological Chemistry,

The Institute for Life

Sciences, the Hebrew University of

Jerusalem, Givat Ram, Jerusalem, il-91904,

Israel

$\mathrm{N}$ de Groot

A Hochberg

Makassed Islamic Charitable Hospital, il-91194, Jerusalem, Israel

M Sughayer

B A Libdeh

S Ayesh

Department of Pathology and Laboratory Medicine, University of Pennsylvania Medical School, 3400 Spruce Street, Philadelphia, PA, 19104-4283, USA

M L Tykocinski

Correspondence to: Dr Ariel, Hadassah University Hospital, Mount Scopus, PO Box 24035, Jerusalem, IL-91240 Israel ariel@hadassah.org.il

Accepted for publication 10 August 2000

\begin{abstract}
Aims-To investigate the expression of the imprinted oncofetal $\mathrm{H} 19$ gene in human bladder carcinoma and to examine the possibility of using it as a tumour marker, similar to other oncofetal gene products. Methods-In situ hybridisation for H19 RNA was performed on 61 first biopsies of bladder carcinoma from Hadassah Medical Centre in Jerusalem. The intensity of the reaction and the number of tumour cells expressing H19 in each biopsy were evaluated in 56 patients, excluding biopsies with carcinoma in situ. The medical files were searched for demographic data and disease free survival.

Results-More than $5 \%$ of cells expressed H19 in 47 of the $56(84 \%)$ biopsies. There was a decrease in the number of cells expressing $\mathrm{H} 19$ with increasing tumour grade (loss of differentiation) $(p=0.03)$. Disease free survival from the first biopsy to first recurrence was significantly shorter in patients with tumours having a larger fraction of $\mathrm{H} 19$ expressing cells, controlling for tumour grade. This was also supported by the selective analysis of tumour recurrence in patients with grade I tumours.

Conclusions-It might be possible to use H19 as a prognostic tumour marker for the early recurrence of bladder cancer. In addition, for the gene therapy of bladder carcinoma that is based on the transcriptional regulatory sequences of $\mathrm{H} 19$, the expression of $\mathrm{H} 19$ in an individual biopsy could be considered a predictive tumour marker for selecting those patients who would benefit from this form of treatment. (F Clin Pathol: Mol Pathol 2000;53:320-323)
\end{abstract}

Keywords: H19; bladder carcinoma; tumour marker

Cancer cells share many features with embryonal cells. These include characteristics linked to reduced differentiation, rapid proliferation rate, and the ability to invade. The main difference between the two types of cells is the coordinated and tight regulation of gene expression in the normal process of embryogenesis. Many of the genes that are expressed during embryogenesis and downregulated with maturation are re-expressed in cancer. These genes have been designated oncofetal or oncodevelopmental genes. Oncofetal genes have been used widely as markers of the reversal of the tissue to a less differentiated phenotype.

Imprinted genes comprise a unique group of genes that play a pivotal role in embryogenesis and fetal development. ${ }^{1}$ These genes are subjected to an epigenetic modification of their expression by silencing one of the two alleles depending on the gamete of origin. The H19 gene was one of the first genes known to be imprinted in mice and humans. ${ }^{2-4}$ It is located on an imprinted domain of human chromosome $11 \mathrm{p} 15.5$ and the syntenic region of mouse chromosome 7. H19 is expressed from the maternal allele and is tightly linked to the imprinted paternally expressed insulin-like growth factor 2 (IGF2) gene, which resides next to it on the same domain. ${ }^{5}$

The $\mathrm{H} 19$ gene is abundantly expressed from the early stages of embryogenesis through fetal life in many tissues and is downregulated postnatally. ${ }^{6-8}$ Its product is an untranslated RNA molecule. ${ }^{9}$ Although its role has been investigated for more than a decade, its biological function is still under debate. ${ }^{10}{ }^{11}$ However, a major role for this gene in embryogenesis is implied by its high degree of evolutionary conservation. ${ }^{12}$

We were the first to document the high expression of the $\mathrm{H} 19$ gene in human bladder carcinoma. ${ }^{813} 14$ The aim of our present retrospective study was to explore the possibility of using it as a tumour marker. We found that the mean fraction of tumour cells expressing $\mathrm{H} 19$ was reduced in parallel with the loss of tumour differentiation and in invasive bladder cancer. Moreover, H19 expression was found to be a marker of early tumour recurrence, independent of tumour grade.

\section{Materials and methods}

First biopsies of transitional cell carcinoma of the urinary bladder were selected from the files of the pathology department at the Hadassah Medical Centre in Jerusalem. Histological grading according to the WHO classification ${ }^{15}$ was performed on the biopsies by one pathologist, a specialist in urological pathology, who was unaware of the in situ hybridisation (ISH) results (GP). Representative paraffin wax blocks from each patient were sectioned and, using the digoxigenin labelled antisense H19 probe, ISH was performed according to Ariel et al (fig 1). ${ }^{16}$ Fetal bladder mucosa was used as a positive control and controls for the specificity of the ISH were used as described previously. ${ }^{16}$

The fraction of cells expressing H19 was defined as "quantity of H19" and was graded as follows: only a few cells $(<5 \%), \pm(0.5)$; up to one third of the cells, $+(1)$; one to two thirds, $++(2)$; more than two thirds, +++ (3). The intensity of the staining was evaluated by

*These authors made an equal contribution to this work. 


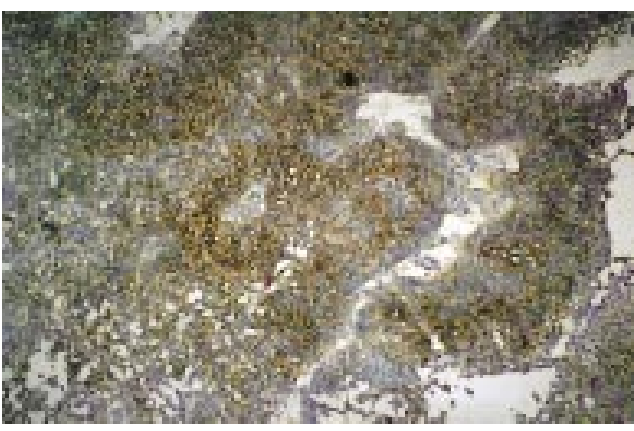

Figure 1 H19 expression in bladder carcinoma as demonstrated by in situ hybridisation, using digoxigenin labelled antisense probes of H19, with Giemsa as a counterstain. In this microscopic field more than two thirds of the tumour cells express H19 (+++).

microscopic examination and graded as no staining (0), weak (1), moderate (2), and high (3).

The demographic and clinical data obtained from the patients' files included age, sex, stage of disease, and the period of time from the first procedure (only in patients with no residual disease) to the first recurrence.

The statistical tests used in our study to evaluate the association of the number of cells expressing $\mathrm{H} 19$ and the intensity of staining with tumour grade and stage included the Kruskal-Wallis (one way ANOVA) and MannWhitney non-parametric tests. Disease free survival was calculated from the first surgical procedure to the first recurrence or last clinic visit. Patients with residual disease after the first procedure were excluded. Kaplan-Meier plots and log rank and Breslow tests were used to evaluate the association of disease free survival with the fraction of H19 expressing cells in the tumour and staining intensity. ${ }^{17}{ }^{18}$ The statistical analysis was performed using SPSS for Windows (version 8.0, SPSS Inc, Chicago, Illinois, USA).

\section{Results}

We studied a total of 61 patients from the Hadassah Medical Centre, of whom 49 were men $(80.3 \%)$ and 12 were women $(19.7 \%)$. The male to female ratio was $4.7: 1$. In Israel the age adjusted incidence rate for bladder carcinoma is 4.7 higher in Jewish men compared with Jewish women, ${ }^{19}$ whereas in the USA the ratio is approximately $3: 1 .^{20}$

The mean age was found to be 68 years (SD, 13). This is similar to the age of patients with bladder cancer in the USA, which is primarily encountered in men 50-70 years (median and mean 64 and 68 years, respectively).

We excluded patients with carcinoma in situ not accompanied by papillary cancer. Of the remaining 56 patients, the expression of $\mathrm{H} 19$ in more then $5 \%$ of the cells was found in 47 of the $56(84 \%)$ tumours. The mean quantity of H19 was calculated for each tumour grade and was found to be 2.02 (SD, 0.90) for grade I carcinoma (32 cases), 1.50 (SD, 0.97) for grade II (10 cases), and 1.18 (SD, 1.12) for grade III (14 cases). The difference was found to be significant $(p=0.03)$ by the KruskalWallis one way ANOVA test (fig 2).
Normal bladder mucosa, when present in the sample, was always negative, as we have reported previously. ${ }^{813}$

Because of the small number of invasive tumours we grouped together all the stages of invasive cancer (superficial and deep). The quantity of $\mathrm{H} 19$ was calculated for tumour stage, and non-invasive tumours $\left(\mathrm{T}_{\mathrm{a}}\right)$ were compared with superficially and deeply invasive tumours $\left(\mathrm{T}_{1}-\mathrm{T}_{4}\right)$. We found that in 39 non-invasive tumours $\left(\mathrm{T}_{\mathrm{a}}\right)$, the mean quantity of H19 expressing cells (1.91 (SD, 1.02)) was significantly higher than in invasive tumours $\left(\mathrm{T}_{1}-\mathrm{T}_{4}\right)$, which had a mean quantity of 1.05 (SD, 0.96; Mann-Whitney test, $\mathrm{p}=0.03$ ) (fig 3).

Disease free survival was calculated for quantity of H19, as defined previously. Only patients with no residual disease, and hence only patients with no evidence of deep invasion, were included in this analysis. For quantity grading 3,2 , and $<2$, the median survival was found to be $8.3,38$, and 51 months respectively ( $p=0.05$ by log rank test; $\mathrm{p}=0.04$ by Breslow test). See fig 4 for survival curves.

The intensity of ISH staining and the combined value of intensity plus quantity was

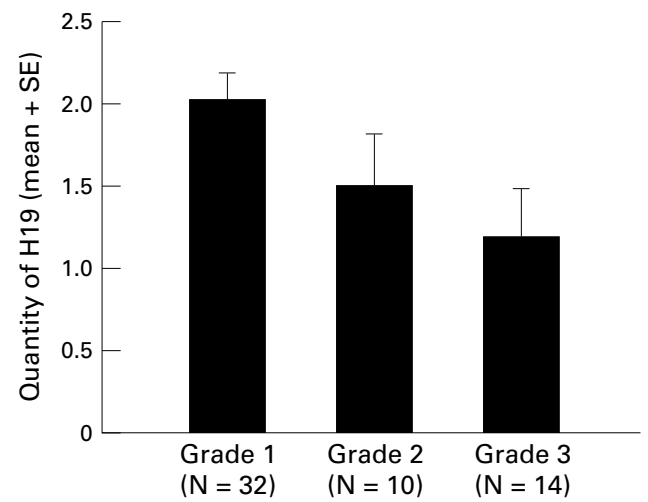

Figure 2 The mean fraction of tumour cells expressing H19 (defined as "quantity of H19") calculated for tumour grade (WHO classification) in 56 patients. The "quantity" was defined as follows: only a few cells (<5\%), $\pm(0.5) ;$ up to one third of the cells, + (1); one to two thirds, ++ (2); more than two thirds, +++ (3). There was a significant decrease in the quantity of H19 with increasing tumour grade (Kruskal-Wallis one way ANOVA, $p=0.03$ ).

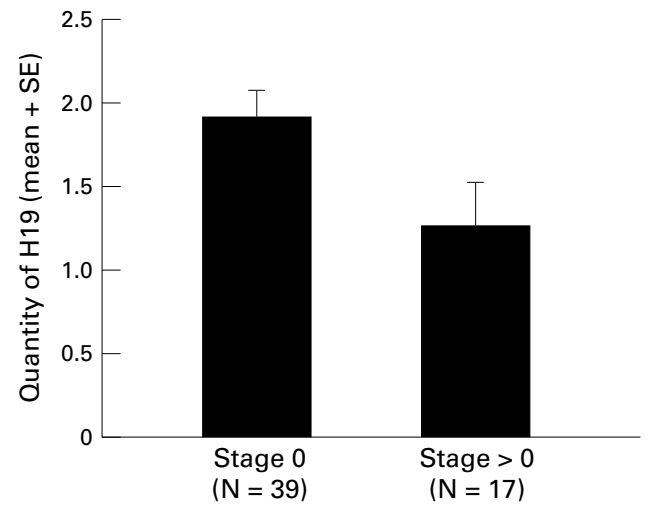

Figure 3 The mean fraction of tumour cells expressing H19 (defined as "quantity of H19") calculated for tumour stage, non-invasive (0) or invasive (>0), of 56 patients. There was a significant decrease of quantity of H19 in invasive tumours (Mann-Whitney test, $p=0.03$ ). 


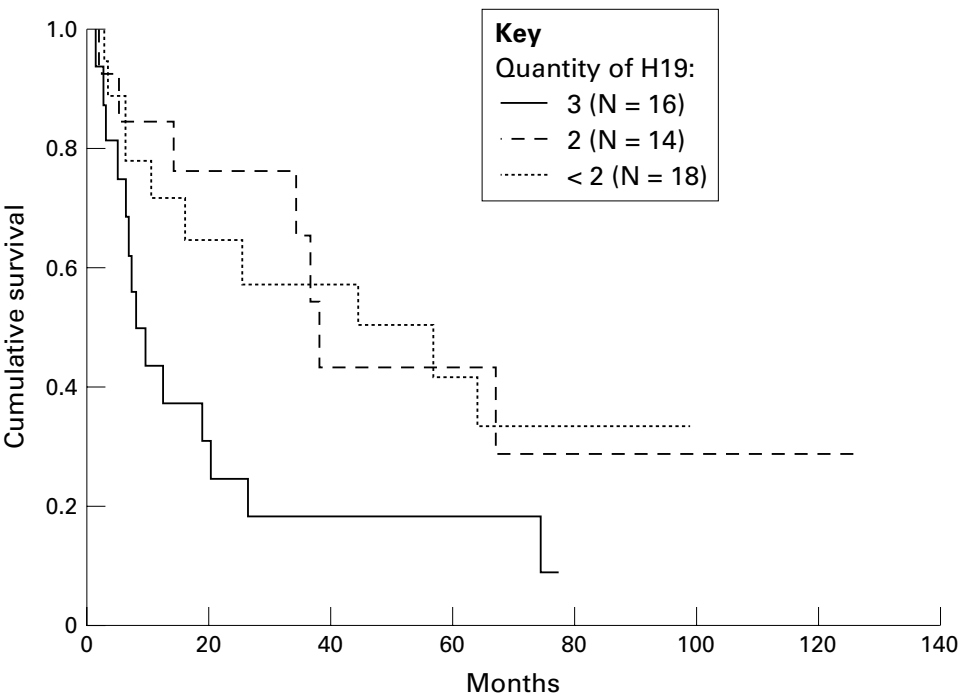

Figure 4 Disease free survival in months of 48 patients with no evidence of residual disease calculated for "quantity of H19" as defined above (see fig 2). The disease free survival was shorter for the quantity of H19 defined as 3 (log rank test, $p=0.05$; Breslow test, $p=0.04$.

not significant in relation to tumour grade, stage, or disease free survival.

Our finding that $\mathrm{H} 19$ expression is more abundant in low grade bladder carcinoma but that it is also a marker of early tumour recurrence prompted us to analyse further the data controlling for grade. The disease free survival in our series was reduced with increasing tumour grade in accordance with the literature. In our series, the median disease free survival for grade I was found to be 34.5 months, for grade II 19.2 months, and for grade III 6.4 months. We then selectively analysed the risk of tumour recurrence for quantity of H19 in those patients with grade I tumours. The median disease free survival for quantity of H19 grading 3, 2, and $<2$ was found to be 8.3, 37.5 , and 54.6 months, respectively $(p=0.03$ by $\log$ rank test; $p=0.02$ by Breslow test).

\section{Discussion}

Cancer has become a major cause of morbidity and mortality in Western society as a result of the increased longevity of humans combined with their increased exposure to carcinogens and other hazards of the industrialised world. The understanding of the basic biological processes involved in carcinogenesis at the level of a single cell, the tissue, and the organism as a whole may lead to better prevention, diagnosis, and treatment of human cancer.

In recent years, we have extensively investigated the expression of the $\mathrm{H} 19$ gene in human bladder carcinoma. ${ }^{813}{ }^{14}$ In a preliminary study of a small number of randomly selected samples we found that H19 was expressed mainly in grades II and III bladder cancer and only rarely in grade I carcinoma. ${ }^{13}$ This impression was found to be inaccurate by our present larger scale study of first biopsies. This could be because of the small number of cases in our previous pilot series, which was biased by the unbalanced ratio of high grade invasive tumours, and did not reflect their relative frequency among bladder carcinomas. In our present study, the ratio of the different grades of bladder carcinoma reflects their prevalence in the population, as well as other demographic data on patients with bladder carcinoma.

We found that the mean fraction of H19 expressing cells was reduced in parallel with the loss of tumour differentiation $(p=0.03)$. Similar findings were obtained when the numbers of cells expressing $\mathrm{H} 19$ were compared for non-invasive and invasive bladder cancer, and a larger fraction of H19 expressing cells was found in the non-invasive tumours $(\mathrm{p}=0.03)$. This is not surprising because the stage of bladder carcinoma invasion correlates well with tumour grade. The reduction of oncofetal gene expression with the progression of tumour grade is well recognised in the case of another oncofetal gene product-carcinoembryonic antigen (CEA) in colon cancer. The serum concentration of CEA is raised in as many as $95 \%$ of patients with well differentiated tumours, whereas it is raised in only $30 \%$ of those with poorly differentiated colonic adenocarcinoma. ${ }^{21}$

This raises the question of the use of $\mathrm{H} 19$ as a tumour marker. Because $\mathrm{H} 19$ functions as an RNA molecule there is no protein product to be detected in the blood or body fluids. This limits the usefulness of $\mathrm{H} 19$ as a tumour marker for cells and tissues. We have shown in our present study that the quantity of H19 expressing cells in bladder carcinoma could be used as a prognostic marker to indicate early tumour recurrence. Its expression (as demonstrated by ISH) could be used as a predictive tumour marker for the selection of a subpopulation of patients who would benefit from gene therapy based on the transcriptional regulatory sequences of $\mathrm{H} 19$.

Gene therapy could be considered as an adjuvant treatment in patients with superficial refractory bladder carcinoma, in whom the tumour recurs despite multiple surgical resections, chemotherapy, and/or immunotherapy (BCG). The latter cause serious local and systemic adverse reactions. ${ }^{22}{ }^{23}$ Gene therapy for cancer is based upon the combination of a cytotoxin with the control elements of a gene highly expressed in cancer cells but not in the normal tissue. After transfection, these control elements activate the cytotoxin in cells that express the specific gene, thereby destroying them. H19 is expressed in a larger fraction of tumour cells in well differentiated non-invasive tumours and, therefore, these tumours are more likely to benefit from gene therapy based on $\mathrm{H} 19$ transcriptional regulatory elements.

Although histological grading and clinical staging are important prognostic factors in bladder cancer, they do not allow an accurate prediction of tumour behaviour within each group. ${ }^{24}$ Scientific progress in molecular biology, immunology, and cytogenetics in the past decade has led to a better understanding of tumour biology and tumour characteristics, and the more accurate evaluation of potential tumour behaviour. An ideal tumour marker is characterised by a high degree of sensitivity and specificity, and provides diagnostic and prognostic information on tumour behaviour 
as well as a prediction of its response to treatment. Some markers can predict recurrence and tumour progression in superficial bladder cancer, as seems to be the case for H19, whereas other markers are better predictors of the behaviour of invasive carcinoma. Tumour progression might occur through several different pathways. Therefore, the evaluation of multiple markers in each tumour will allow a more accurate and individual therapeutic approach.

We suggest that $\mathrm{H} 19$ should be considered a tumour marker that combines prognostic and predictive value in patients with refractory superficial cancer. Those patients with more H19 positive cells are potentially at higher risk of recurrent disease and should benefit most from tumour targeted gene therapy using the transcriptional regulatory elements of $\mathrm{H} 19$.

We suggest that the evaluation of H19 expression in bladder cancer, especially in biopsies of grade I superficial carcinoma, could be used for the prediction of tumour recurrence and also for the prediction of the response to adjuvant gene therapy based on the transcriptional regulatory sequences of $\mathrm{H} 19$.

The authors thank Dr M Baras for the professional statistical analysis. This work was supported by the Trilateral Grant analysis. This work was supported by the Trilateral Grant Germany, and by the NIH grant number 1RO1CA69646$01 \mathrm{~A} 1$.

1 Tilghman SM. The sins of the fathers and the mothers: genomic imprinting in mammalian development. Cell 1999;96:185-93.

2 Bartolomei MS, Zemel S, Tilghman SM. Parental imprinting of the mouse H19 gene. Nature 1991;351:153-5.

3 Rachmilewitz J, Goshen R, Ariel I, et al. Parental imprinting of the human H19 gene. FEBS Lett 1992;309:25-8.

4 Zhang Y, Tycko B. Monoallelic expression of the human H19 gene. Nat Genet 1992;1:40-4

5 Zemel S, Bartolomei MS, Tilghman SM. Physical linkage of the mammalian imprinted genes $\mathrm{H} 19$ and insulin-like growth factor 2. Nat Genet 1992;2:61-5.

6 Goshen R, Rachmilewitz J, Schneider T, et al. The expression of the H19 and IGF2 genes during human embryogenesis and placental development. Mol Reprod Dev 1993;34:374-9.

7 Lustig O, Ariel I, Ilan J, et al. The expression of the imprinted gene H19 in the human fetus. Mol Reprod Dev 1994;38:239-46

8 Ariel I, Ayesh S, Perlman EJ, et al. The product of the imprinted H19 gene is an oncofetal RNA. F Clin Pathol: Mol Pathol 1997;50:34-44.

9 Brannan CI, Dees EC, Ingram RS, et al. The product of the H19 gene may function as an RNA. Mol Cell Biol 1990;10: 28-36.

10 Lustig-Yariv O, Schulze E, Komitowski D, et al. The expression of the imprinted genes H19 and IGF-2 in choriocarcinoma cell lines. Is H19 a tumor suppressor gene? Oncogene 1997;15:169-77.

11 Ariel I, de Groot N, Hochberg A. The imprinted H19 gene expression in embryogenesis and human cancer. Am f Med Genet 2000:91:46-50.

12 Hurst LD, Smith NGC. Molecular evolutionary evidence that H19 mRNA is functional. Trends Genet 1999;15:1345.

13 Ariel I, Lustig O, Schneider T, et al. The imprinted H19 gene as a tumor marker in bladder carcinoma. Urology 1995;45:335-8.

14 Elkin M, Shevelev A, Schulze E, et al. The expression of the imprinted $\mathrm{H} 19$ and IGF-2 genes in human bladder carcinoma. FEBS Lett 1995;374:57-61.

15 Mostofi, FH, Sobin, LH, Torloni, H. Histological typing of urinary bladder tumors. International classification of tumors, No. 10. Geneva: World Health Organisation, 1973.

16 Ariel I, Miao HQ, Ji XR, et al. The imprinted H19 oncofetal RNA is a candidate tumor marker for hepatocellular carcinoma. F Clin Pathol: Mol Pathol 1998;51:21-5.

17 Kaplan EL, Meier P. Nonparametric estimation from incomplete observation. Fournal of the American Statistics Association 1958;53:457-81.

18 Miller RG. Survival analysis. New York: John Wiley, 1981:44-102.

19 Israel Cancer Registry. Ministry of Health: Trends in cancer incidence and mortality in Israel 1970-1995. Tel Hashomer: Israel Centre for Disease Control and Israel Cancer Association, Publication No. 207, 1998.

20 Scher HI, Shipley WU, Herr HW. Cancer of the bladder. In: DeVita VT, Jr, Hellman S, Rosenberg SA, eds. Principles and practice of oncology. Philadelphia: Lippincott-Raven, 1997:1300-22

21 Armitage NC, Davidson A, Tisikos D, et al. A study of the reliability of carcinoembryonic antigen blood levels in following the course of colorectal cancer. Clin Oncol 1984: 10:141-7.

22 Witjes JA, Debruyne FMJ. Optimal management for superficial bladder cancer. Eur f Cancer 1991:27:330-3.

23 Goldberg MR, Heimbrook DC, Russo P, et al. Phase I clinical study of the recombinant oncotoxin TP40 in superficial bladder cancer. Clin Cancer Res 1995:1:57-61.

24 Stein JP, Grossfeld GD, Ginsberg DA, et al. Prognostic markers in bladder cancer: a contemporary review of the literature. F Urol 1998:160:645-59. 